intensity ratio $\mathrm{N}_{1} / \mathrm{N}_{2}$ increases generally with velocity and the density of the bombarding electric rays, and in nitrogen-argon mixtures it increases very much when the nitrogen concentration diminishes. With very small concentrations $\mathrm{N}_{\mathbf{1}}$ predominates as compared with $\mathrm{N}_{2}$. This effect indicates that $\mathrm{N}_{1} / \mathrm{N}_{2}$ increases as the nitrogen particles get smaller, and it may thus account for the predominance of the auroral line 5577 in the auroral spectrum.

The great variability of $\mathrm{N}_{1} / \mathrm{N}_{2}$ makes it difficult to determine exactly the minimum cathode ray velocity necessary for producing the two bands. Perhaps they require the same velocity, only that the intensity of $\mathrm{N}_{1}$ usually is very small at small velocities. At the present time, I have been able to follow $\mathrm{N}_{2}$ down to velocities corresponding to 78 volts, and $\mathrm{N}_{1}$ down to I65 volts.

A non-luminous layer of solid nitrogen was not made luminous by ultraviolet light from a condensed aluminium spark. X-rays, however, produced the ordinary afterglow.

When the layer is in the state showing the persistent afterglow, conditions are different. In this case light from an ordinary incandescent lamp with a tungsten filament produced a very marked increase in the intensity of the afterglow. In some cases the intensity underwent very marked periodic variations with periods of 5-6 seconds, and I could count 8-9 periods.

Layers of solid oxygen, ammonia, and argon have been bombarded with both cathode rays and canal rays, and a layer of nitrous oxide with canal rays only. With the exception of argon, the light effect was feeble and gave no afterglow. The fairly strong effect observed from an argon layer was to a great extent due to traces of nitrogen, which produced a weak afterglow and a strong emission of $N_{1}$ and the canal-ray bands of nitrogen. The afterglow showed only the line $\mathrm{N}_{2}$ and no other visible light in the spectrum. Thus argon itself gives no afterglow, and the real argon effect, although somewhat stronger, perhaps, than in the case of oxygen ammonia and nitrous oxide, is an effect of the same type as shown by these gases.

The experiments on layers of various substances thus show that the light effect from nitrogen at temperatures below $35.5^{\circ}$, which is applicable to the auroral spectrum, is a light effect of a unique and singular type.

\title{
The Beam System of Radio Telegraphy.
}

THE paper read by Senator Marconi to the Royal Society of Arts on July 2, and published in the Journal of the Society for July 25, describing the results he has obtained over very long distances by short wave directional radio telegraphy, is one of great importance and marks an epoch in the development of long distance radio communication. Mr. Marconi reminds us that more than twenty-eight years ago he showed Sir William Preece the transmission and reception of signals over a distance of nearly two miles by a "beam" system, using short waves and reflectors. Curiously enough, at that time he could only transmit signals by means of an antenna over a

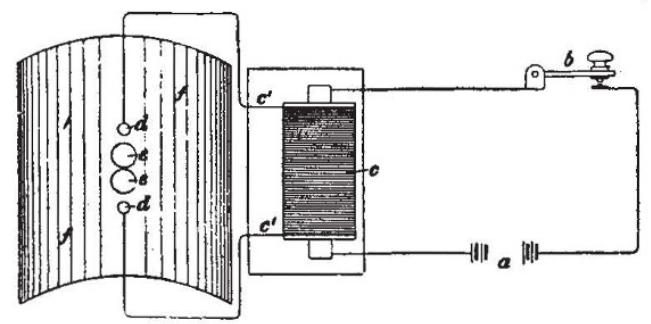

Fig. I. - Spark transmitter and sheet metal reflector, 1896.

distance of half a mile. The rapid and spectacular progress made, however, by the long wave system in those early days diverted attention from short wave research, although the latter could be emitted in beams in definite directions.

In 1899 , Mr. Marconi read a paper to the Institution of Electrical Engineers in which he pointed out that a short wave system would be of value in connexion with lighthouses and lightships in foggy weather, enabling them to locate dangerous points. He also projected a beam of waves across the lecture room, a bell ringing only when the reflector faced the receiver (Figs. I and 2).

In I9r6, in conjunction with Mr. C. S. Franklin, he again began to make researches with directive beams. The reflectors used at first were not solid sheets of metal, but consisted of wires forming a cylindrical parabolic reflector, the antenna forming the focal line of the cylinder (Fig. 3). The reflectors now used consist of a grid of antennæ and a grid of reflecting wires arranged parallel to one another (Fig. 4). Special arrangements have to be made so as to ensure that the phase of the oscillations in all the wires is the same. The great value of reflectors was demonstrated by experiment, the energy received being increased about two hundredfold by their use.

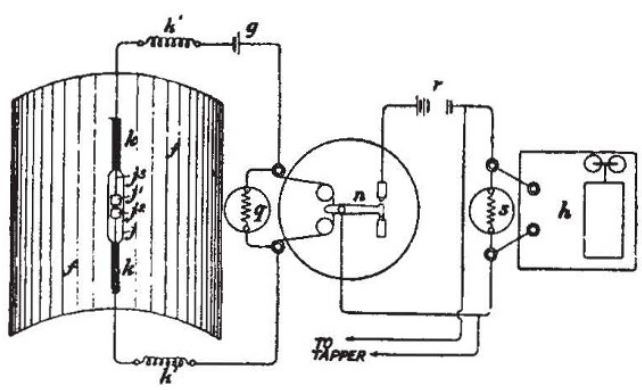

Fig. 2,-Coherer receiver and sheet metal reflector, 1896.

Many tests were carried out between the steam yacht Elettra and a small station erected at Poldhu which emitted waves about roo metres in length, the frequency therefore being about $3,000,000$. One definite result obtained was that the strength of the signals received during the hours of daylight varied inversely with the mean altitude of the sun over the space intervening between the two stations. It is wrong, therefore, to refer to distances covered during daylight as "day ranges." It shows also that the tests which were carried out partly within the tropics during the months of May and June were made under very unfavourable conditions.

NO. 2862 , VOL. II 4 ] 
The results prove quite definitely that the absorption factor given in the well-known Austin formula does not apply to short wave phenomena. It can be replaced by a factor which is approximately a linear function of the mean altitude of the sun calculated on the great circle of the earth which passes through the two stations. In regard to atmospheric disturbances and others, the origin of which is unknown, these appeared to be less troublesome during daylight than when working with a long wave system. During night time, even up to distances of more than 2000

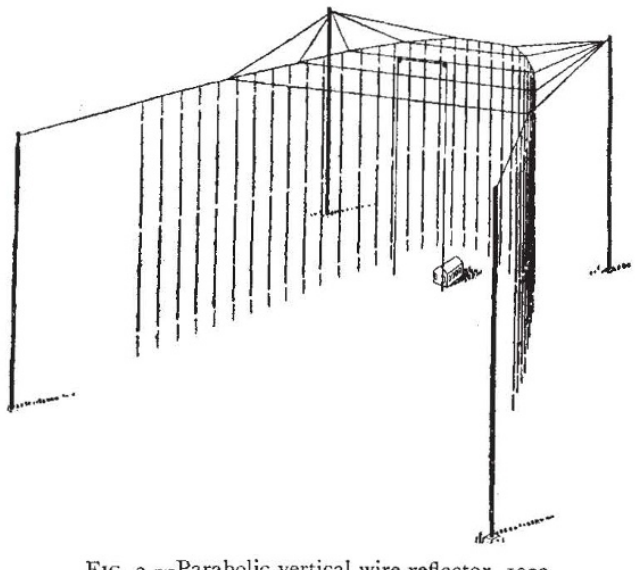

FiG. 3.-Parabolic vertical wire reflector, 1923.

miles, the signals received were so strong that extraneous disturbances caused no appreciable interference.

During the tests, the Poldhu transmitter consisted of eight glass valves in parallel, the input being only I 2 kw. The radiated energy concentrated by the parabolic reflector in the direction of Cape Verde was about $9 \mathrm{kw}$. If no reflector had been used. about I $20 \mathrm{kw}$. would have been necessary to get a beam in that direction of the same intensity. The receiving aerial was a vertical wire at a height of twenty metres above sea-level. The first series of tests was carried out without the transmitting reflector. Day signals were received up to Seville, which is 780 miles from Poldhu, although practically the whole of Spain, consisting of more than 300 miles of high and mountainous country, lay between the sending and the receiving station. At Gibraltar $(820$ miles), better signals were obtained, as the yacht was anchored in a more open space.

For greater distances the reflector wires were used at Poldhu. At Madeira (1250 miles) good signals were obtained, using $\mathrm{I} 2 \mathrm{kw}$. at the sending station. At St. Vincent (2230 miles), Cape Verde Islands, it was still possible to get a few hours' daylight reception after sunrise and before sunset. The night signals continued to arrive with apparently unabated strength although the distance had been increased to about double what it was at Madeira.

The strength of the night signals at St. Vincent was estimated to be about 500 microvolts per metre of aerial wire, and no trouble was experienced from any kind of interference. It was calculated that night signals would continue to be received at St. Vincent even if the power at Poldhu were reduced to the tenth of a kilowatt.

After this voyage, the station at Poldhu was improved, the power being increased to $20 \mathrm{kw}$. Since February of this year further tests have been made. A special short wave receiver was installed on the s.s. Cedric, and reception tests were carried out with Poldhu during a journey of the vessel to New York and back. No reflectors were used at either end. The results obtained confirm the earlier experiments. Daylight signals could be received up to a distance of I400 nautical miles.

During this test one surprising result was obtained. Mr. E. T. Fisk, of Sydney, Australia, reported by cable that he could receive the Poldhu transmissions perfectly well every day at his house from 5 to 9 P.M. (G.M.T.). He also received them between 6.30 and 8.30 A.M. He used an improvised receiver consisting of a 2 -stage high frequency tuned plate and grid with one rectification. Every word that was sent had been read, and Mr. Fisk stated that the signals were better than any he had received from the high power station at Carnarvon. Further experiments on communicating with Sydney were made, and consistently good results were obtained.

The experimenters conclude that during the morning period the waves start from England to Australia in a westerly direction. The waves cross the Atlantic and Pacific Oceans, a distance of approximately $x 2,220$ nautical miles. In the evening they travel in an easterly direction over Europe and Asia. This is the shortest route, being only 9380 miles.

In Canada, at Montreal, reception was possible for sixteen hours out of the twenty-four. A successful wireless telephonic test was made with Sydney on May 30 , the speech being intelligible and easily heard. It is noteworthy that this great distance was obtained without the use of a reflector at either end. The use

$$
\text { NO. } 2862 \text {, voL. I I } 4 \text { ] }
$$

of reflectors would doubtless be a great advantage in practice as it would both strengthen the received waves and cut out all the extraneous disturbances except any which are proceeding in the line of the beam.

The aerials used were never worked to anything approaching the limit of their carrying capacity. It would be quite possible in practice to superimpose several waves and thus send several services simultaneously from the same aerial. The speed of working obtainable by using short waves is very much higher than that obtainable by the long waves now in general use. 
Mr. Marconi calculates that the speed of signalling with a Ioo-metre wave, having a frequency of three million, will probably be a hundred times as great as that obtained with a frequency of 30,000 , which is of the order of those that it is proposed to use for the Imperial Stations.

Further tests in June last were made between Poldhu and a small receiving station at Buenos Aires in the Argentine ( 5820 miles). A parabolic reflector was employed to concentrate the energy stream towards the Argentine. Although the power radiated was only $\mathrm{I} 7 \mathrm{kw}$., strong signals were received for more than ten hours a day at Buenos Aires.

Mr. Marconi is strongly of opinion that by means of these small and inexpensive stations a far greater number of words could be transmitted between England, India, and distant British Dominions than would be possible by means of the previously planned powerful and expensive stations. The communications also would be much more secret than that obtainable by any of the present systems. In conclusion, he expresses his high appreciation of the excellent work done by Mr. C. S. Franklin in this connexion.

\section{Obituary.}

Sir George Beilby, F.R.S.

SIR GEORGE BEILBY died on July $3 \mathrm{I}$, in his seventy-fourth year, and when he had just laid aside the harness by which he had so long applied his talents with great effect in varied fields. His death caused widespread regret and directed attention to a notable record of public service in the linked relations of science, industries and citizenship. Fortunately for industry his early work brought him into close touch with the details of production as well as with scientific problems which confronted the chemical manufacturer. His skill and thoroughness in investigation, and his clear appreciation of the conditions of large scale work, enabled him to make successive additions of much value to the methods of industry. His relations with commercial production became such that he was in a position to follow up his researches in science by investigation of those of their applications which seemed to be promising. The success which from time to time attended his steady and enthusiastic labour enabled him to give to public purposes much of his energy, as well as to afford substantial support towards the advancement of science and the training of promising recruits for the ranks of scientific workers. Withal, the man and his life will remain in the minds and hearts of many, young and old, as a beacon no less bright than his work.

The son of Dr. G. T. Beilby, a well-known medical practitioner in Edinburgh, Sir George was born there in 1850 . He was educated in Edinburgh schools and the University, and he joined the staff of the Oakbank Oil Company as a chemist in 1870 . This appointment marked the opening of his professional work, which falls into three periods commencing in 1870,1890 , and I9I4 respectively.

I870-I890.-A few years after joining the staff at Oakbank, Beilby became manager, and he held this position until about I890; thus from I870 to $I 890$ his work centred on the Scottish oil industry. He introduced improvements in several sections of the work, the most important being the use of large volumes of superheated steam which was passed into and through the spent shale in the retort, converting the carbon of the shale into water-gas and the nitrogen largely into ammonia. This procedure had several notable advantages, of which the main one was that it more than doubled the yield of ammonia-a result which saved the Scottish oil industry from extinction during the years of severe competition by petroleum.

The minor advantages of the process were: (I) the water gas, formed and heated in the lower part of the retort, conveyed heat internally to the shale in the upper portion, thus assisting to distil the shale at moderate heat; and (2) the removal of carbon from the spent-shale was practically complete, so that fires in the spent-shale " bings" which made these a nuisance in their neighbourhood were avoided. Beilby erected his original retort, operated on these lines, at Oakbank, but later he associated himself with the late Mr. James Young, who was experimenting on similar lines, and together they brought out the "Young and Beilby" retort (patented $\mathrm{I} 88 \mathrm{I}$ ), which is the prototype of the existing forms.

It is of interest to note that the use of steam in gas production with the purpose of recovering the nitrogen of the coal as ammonia was first proposed by Beilby, who practised it on an industrial scale at Oakbank Oilworks.

Towards the close of the first period of his work Beilby's attention had been attracted by the advent of the McArthur Forrest patents (1887) for the extraction of gold from its ore by means of cyanides. The probable demand for cyanides appeared to him to open an extensive field for chemical industry, and he proceeded to investigate the possibilities of preparing cyanide cheaply. This led shortly to his putting down a small factory near Edinburgh, where he produced the material in fair quantities at a price much lower than that reached by other makers.

r890-r9r4.-Beilby laid his cyanide process and its results before the directors of the Cassel Gold Extracting Co. of Glasgow (now the Cassel Cyanide Co., Glasgow). His process was accepted, and he became a director and partner in the firm. The process was used exclusively and profitably by this Company until I900, when Castner introduced a new process for cyanide manufacture, on the development of which Beilby and Castner worked together. The improved process which they worked out was adopted by the Cassel Cyanide Company. At this time Beilby joined the board of directors of the Castner Kellner Alkali Co., Glasgow, and until the outbreak of war he took a leading part in the development of the two companies mentioned.

While this period consolidated Beilby's position as one of the pioneers and leaders of recent progress in chemical industries, it also brought to the front a parallel line of his activities in research-the using of fuel-and in this connexion it led to a steady increase

NO. 2862, VOL I I 4 ] 